\title{
ON THE PLATINUM POINT ELECTROLYTIC DETECTOR FOR ELECTRICAL WAVES.
}

\author{
By L. W. Austin.
}

The electrolytic wave detector first described by Fessenden ${ }^{1}$ and shortly afterward by Schlömilch, ${ }^{2}$ consists essentially of a cell having as one electrode a fine point usually of platinum and a second larger electrode of platinum or some other metal. The cell in its most effective form contains an electrolyte, the decomposition products of which are gaseous. When an electromotive force is applied to such a cell, powerful polarization ensues, so that scarcely any current passes unless the electromotive force exceeds a certain critical value. When electrical oscillations pass through the cell, the resistance is decreased and the current is for the moment increased only to return to its former small value as soon as the waves cease. This phenomenon has been the subject of several investigations, but the conclusions reached by the several investigators ${ }^{3}$ have not been entirely in accord either in regard to the theory or the action of the instrument. According to Schlömilch and De Forrest it is highly sensitive to waves only when the point electrode is positive, and but very slightly so with negative polarization. Fessenden, and Rothmund and Lessing, on the other hand, claim that the cell is almost equally sensitive when the point is negative.

${ }^{1}$ R. A. Fessenden, Barretter U. S. patent No. 72733I. May 5, 1903, and Electrotechn. Zs. 24, p. 586 and I0I5. I903. A very similar instrument seems to have been used by M. I. Pupin for detecting small alternating currents. See Bulletin Am. Phys. Soc. I, p. 2I. Igoo.

${ }^{2}$ W. Schlömilch, Electrotechn. Zs. 24, p. $959 . \quad$ I 903.

${ }^{3}$ M. Reich, Physik. Zs. 5, p. 338 . 1904. L. DeForrest: Address before the Elec. Congress, St. Louis. I904. V. Rothmund and A. Lessing, Ann. d. Physik., I5, p. 193. I904. 
Fessenden holds that the decrease in resistance is largely a heat effect due to the energy of the waves, although other effects are mentioned in his patents, among them being the breaking down of polarization, and chemical action under the combined influence of waves and direct current, a phenomenon which has been already observed by Margules, ${ }^{4}$ Ruer, ${ }^{5}$ and others in the case of combined direct and alternating currents of lower frequency. Schlömilch advances no theoretical explanation, while Reich, and Rothmund and Lessing, ascribe the effect to a depolarizing influence of the waves, and the former also suggests chemical action. Rothmund and Lessing look upon the phenomenon in part at least as a type of rectification analogous to that of the aluminum rectifier. Schlömilch, and Rothmund and Lessing have also made an interesting study of the action of cells in which the electromotive force is supplied by the cell itself, the large electrode being of a metal different from the point. This is also the principle of the wave detector patented by Shoemaker.

The present work was taken up with the purpose, first, of studying the action of alternating currents of low frequency on the detector; second, the behavior of point electrodes of different sizes; third, the sensitiveness with different electrolytes; and finally, it was hoped that the results would explain the conflicting conclusions of the different experimenters and perhaps throw some light on the real nature of the phenomenon.

\section{EXPERIMENTS WITH SLOW ALTERNATIONS.}

It was thought that alternating currents of low frequency would give conditions which would be more reliable and more easily varied than would more rapid oscillations, and it was therefore determined to begin with currents of this character. The first cell constructed was filled with 30 per cent $\mathrm{H}_{2} \mathrm{SO}_{4}$. The large electrode was of platinum foil having an area of about $2 \mathrm{sq} . \mathrm{cm}$. The small point was of $0.2 \mathrm{~mm}$ platinum wire sealed into glass and broken off short. A point of this sort is not sensitive to any but very strong electrical waves but is highly so to slower oscillations. Afterward other

${ }^{4}$ M. Margules, Wied. Ann. 65, p. 629, I898; 66, p. 540, 1898.

${ }^{5}$ II. Ruer, Zeitschs. f. phys. chem. 44, p. 8I, I903. 
points, both smaller and larger, were used. The arrangement of the apparatus, which is shown in Fig. I, was as follows:

The cell $B$ was placed in series with a potentioneter $P$ from which varying direct electromotive force could be applied, and a galvanometer $G$, which served to measure the current flowing through the cell. At $(a)$ the circuit was broken and two wires led down to a fall of potential wire through which a known alternating current flowed. From this, by means of sliding contacts, any desired alternating electro-motive force could be impressed on the cell $B$.

The amount of direct electromotive force applied to the cell was in general limited by the necessity of keeping the initial galvanometer deflection small, although in some cases

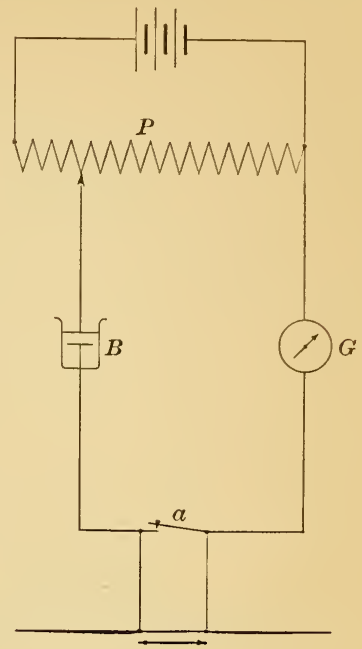

Fig. 1. this was accomplished by putting the galvanometer in shunt in a circuit which contained a second potentiometer.

TABLE I

$$
\mathrm{H}_{2} \mathrm{SO}_{4} \text { (30 per cent.) See Fig. } 2 .
$$

\begin{tabular}{|c|c|}
\hline Polarizing E. M. F. I.45 volts. & $\begin{array}{l}\text { Point } 0.03 \mathrm{~mm} \text { wire. Alternating current } 60 \\
\text { Point Anode }\end{array}$ \\
\hline Alt. E. M. F. & Increase in Direct Current in Cell \\
\hline 0.0003 volts & $0.002 \times 10^{-6} \mathrm{amp}$ \\
\hline .0015 & .010 \\
\hline .0030 & .022 \\
\hline .009 & .111 \\
\hline .012 & .160 \\
\hline .015 & .250 \\
\hline .024 & .610 \\
\hline .027 & .780 \\
\hline .030 & .900 \\
\hline
\end{tabular}

Table I shows the increase in the direct current due to varions small alternating electromotive forces on a cell, the point electrodes 


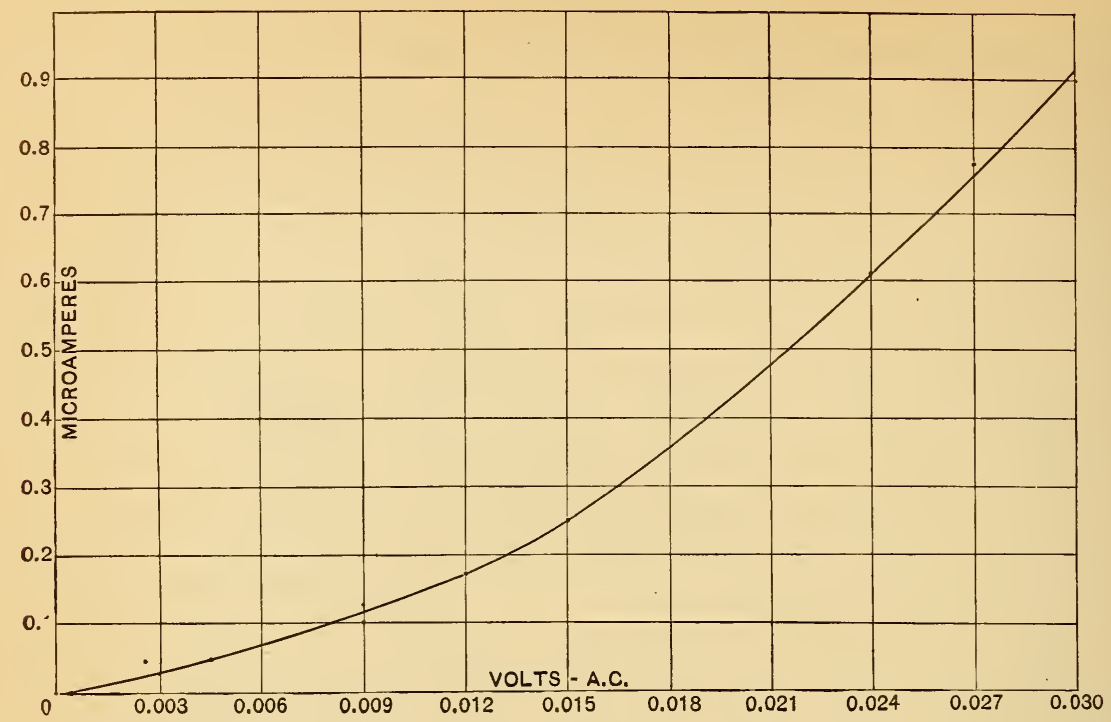

Fig. 2.

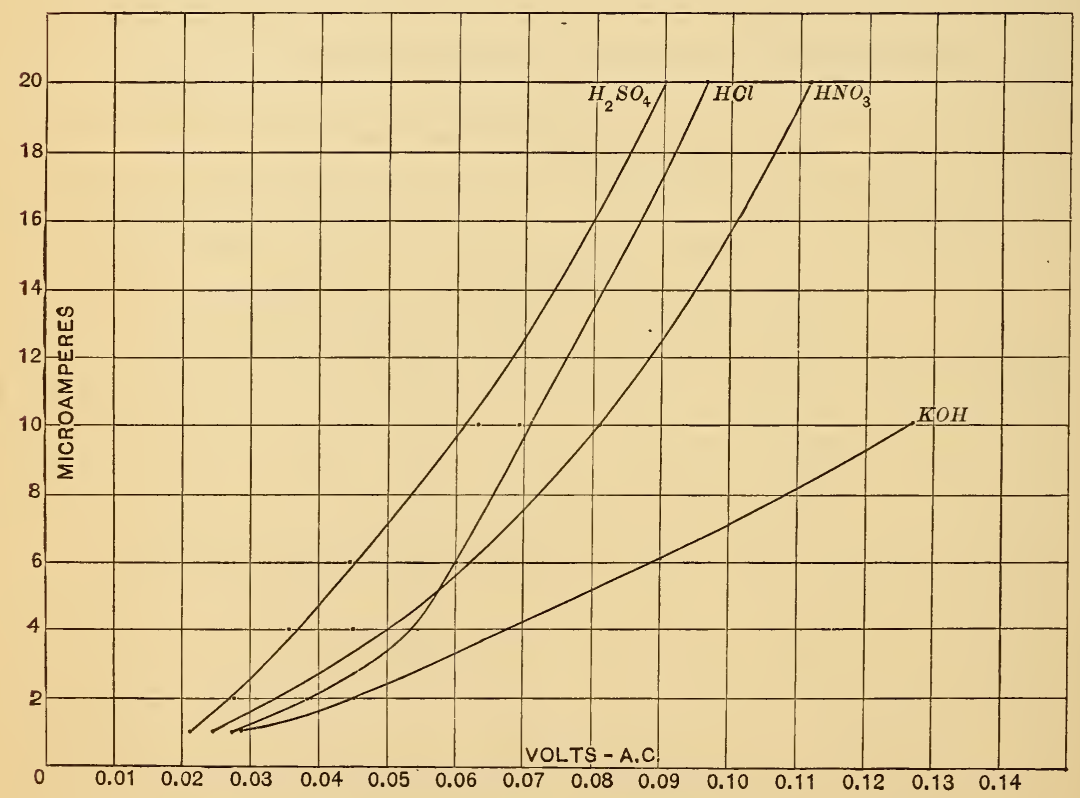

Fig. 3. 
of which consisted of $0.03 \mathrm{~mm}$ wire broken off short in glass and polarized positively with I.45 volts. Table II shows the sensitive-

\section{TABLE II}

Polarizing E. M. F. I.4 volts. Diameter of Pt point $0.2 \mathrm{~mm}$. Alternating Current 60 . See Fig. 3.

$\mathrm{HCl}(50 \%)$
Point Anode

Initial Direct Current $i=20 \times$ 10 $^{-6}$ amp.

Alt. E. M. F.

Increase in $i$

$\begin{array}{ll}0.027 & 1 \times 10^{-6} \mathrm{amp} . \\ .039 & 2 \\ .054 & 4 \\ .060 & 6 \\ .069 & 10 \\ .096 & 20\end{array}$

Point Cathode

Initial Direct Current $i=40 \times 10^{-6}$ amp.

\begin{tabular}{cc}
0.019 & $1 \times 10^{-6}$ \\
.030 & 2 \\
.039 & 4 \\
.048 & 6 \\
.063 & 10 \\
.090 & 20 \\
\multicolumn{2}{c}{} \\
\multicolumn{3}{c}{ Point Anode } \\
Initial Current $i=60 \times$ I0 $^{-6}$ amp.
\end{tabular}

Alt. E. M. F.

E. F. Increase in

0.024

.033

.045

.060

.081

.111
$1 \times 10^{-6}$ amp.

2

4

6

10

20
$\mathrm{H}_{2} \mathrm{SO}_{4}(30 \%)$. Point Anode Initial Current $i=\mathbf{x} 2 \times$ 10 $^{-6}$ a mp.

Alt. E. M. F. Increase in $i$

$\begin{array}{ll}0.021 & 1 \times 10^{-6} \mathrm{amp} . \\ .027 & 2 \\ .035 & 4 \\ .045 & 6 \\ .063 & 10 \\ .090 & 20\end{array}$

$\mathrm{KOH}(50 \%)$

Point Anode

Initial Current $i=\mathrm{ro} \times \mathrm{I0}^{-6} \mathrm{amp}$. Alt. E. M. F. Increase in $i$

$\begin{array}{ll}0.027 & 1 \times 10^{-6} \mathrm{amp} . \\ .045 & 2 \\ .066 & 4 \\ .090 & 6 \\ .126 & 10\end{array}$

$\mathrm{HNO}_{3}(20 \%)$ (Point $0.03 \mathrm{~mm}$ diam.) Point Anode

Initial Current $i=10 \times 10^{-6}$ amp. Alt. E. M. F. Increase in $i$

$\begin{array}{rc}0.027 & 1 \times 10^{-6} \\ .039 & 2 \\ .051 & 6 \\ .087 & 10 \\ .135 & 20\end{array}$

Point Cathode Initial Current $i=50 \times 10^{-6}$ amp.

Alt. E. M. F. Increase in $i$

$\begin{array}{ll}0.030 & 1 \times 10^{-6} \\ .042 & 2 \\ .057 & 4 \\ .069 & 6 \\ .087 & 10 \\ .169 & 20\end{array}$


ness of different electrolytes to higher alternating electromotive forces. The polarizing electromotive force was in each of these cases sufficient to give maximuin sensitiveness. This table shows the very approximate equality of sensitiveness of positively and negatively polarized points for alternating currents of low frequency. It is also seen that the $0.2 \mathrm{~mm}$ points are not less sensitive than the $0.03 \mathrm{~mm}^{6}$ In Table III is shown the relation between sensitive-

TABLE III

\begin{tabular}{|c|c|c|}
\hline \multirow{3}{*}{$\begin{array}{l}\text { Polarizing } \\
\text { E. M. F. }\end{array}$} & \multicolumn{2}{|c|}{$\begin{array}{l}\mathrm{HNO}_{3}(20 \text { per cent }) \\
\text { Diameter of Pt. point o.2 mm. Alt. E. M. F. o.I volt } \\
\text { Point Anode }\end{array}$} \\
\hline & & \\
\hline & Initial & Increase with Alt. Current \\
\hline 0.77 volts. & $0.5 \times 10^{-6} \mathrm{amp}$. & $0.5 \times 10^{-6} \mathrm{amp}$ \\
\hline 0.91 & 2.0 & 3.0 \\
\hline 1.02 & 6 & 9.0 \\
\hline 1.07 & 5 & 10 \\
\hline 1.09 & 7 & 18 \\
\hline 1.12 & 12 & 20 \\
\hline 1.17 & 11 & 22 \\
\hline 1.30 & 50 & 22 \\
\hline 1.38 & 75 & 20 \\
\hline
\end{tabular}

TABLE IV

\begin{tabular}{|c|c|c|}
\hline \multirow{3}{*}{$\begin{array}{l}\text { Polarizing } \\
\text { E. M. F. }\end{array}$} & \multicolumn{2}{|c|}{$\begin{array}{l}\mathrm{H}_{2} \mathrm{SO}_{4}(30 \text { per cent }) \\
\text { Pt. point } 0.2 \mathrm{~mm} \text {. Alt. E. M. F. o.I volt. } \\
\text { Point Cathode. }\end{array}$} \\
\hline & \multicolumn{2}{|c|}{ Direct Current } \\
\hline & Initial & Increase with Alt. Current \\
\hline 0.26 volts. & $0.8 \times 10^{-6} \mathrm{amp}$. & $+0.55 \times 10^{-6} \mathrm{amp}$ \\
\hline .52 & 1.2 & +.55 \\
\hline .78 & 2.5 & -.20 \\
\hline 1.04 & 3.5 & -.40 \\
\hline 1.17 & 4.2 & -.20 \\
\hline & - & +.80 \\
\hline
\end{tabular}

ness and polarizing electromotive force. At about the point when the direct current begins to increase, the sensitiveness rises suddenly and remains constant or decreases slightly. The position of this

\footnotetext{
${ }^{6}$ When the $0.2 \mathrm{~mm}$ wire was not broken off at the surface of the glass into which it was sealed, but was allowed to protrude about $4 \mathrm{~mm}$, the sensitiveness was decreased.
} 
point of rise in sensitiveness does not always correspond to the same polarizing electromotive force, but changes according to the conditions of the surface of the point in a way which is not yet understood.

Perhaps the most peculiar phenomenon noticed in the work is shown in Table IV. Here it is seen that with negative polarization on the point for small direct electromotive force on the cell, the direct current is diminished instead of increased when the alternating electromotive force is applied. This effect appears only occasionally and is less regular than the more common increase in current. It sometimes extends to much higher polarizations, and frequently there seems to be a combination of the two phenomena resulting in almost entire insensibility. ${ }^{7}$

\section{EXPERIMENTS WITH ELECTRICAL WAVES.}

In order to study the action of the electrolytic wave detector in the sphere in which it has the greatest practical interest, experiments were undertaken using electrical waves as the source of excitation. It was thought best to work only with waves of feeble intensity, partly because these are the only variety which are of interest in wireless work, and partly because preliminary experiments indicated that with powerful waves the action of the detector showed anomalies which it was not desired at this time to investigate. One source of waves used in the experiments was a small coil only ro cm long run by two dry cells and capable of giving a spark perhaps I mm long. This was provided with vertical wires above and below, each about $50 \mathrm{~cm}$ in length serving as a kind of aerial. This sending apparatus was set up about 20 feet from the receiver, which was not supplied with an aerial. The key in the primary circuit of the small coil was operated by means of a string by the observer at the receiver. Signals were also sent frequently from the station of the National Electric Signaling Company in Washington by courtesy of Professor Fessenden. The station is about 6 miles from the Bureau, but as the Bureau aerial is very low and our instruments were not in tune, the signals were about as

${ }^{7}$ This seems to be unconnected with the fact, first noticed by Fessenden, that with high polarizing electromotive force oscillations sometimes increase the resistance, which is probably due to the formation of large bubbles and occurs both with positive and negative polarization. 
loud as those received at the Washington station of the company from a corresponding station I 30 miles away.

In this work the chief questions to be considered, were, first, the relation between the sensitiveness of the

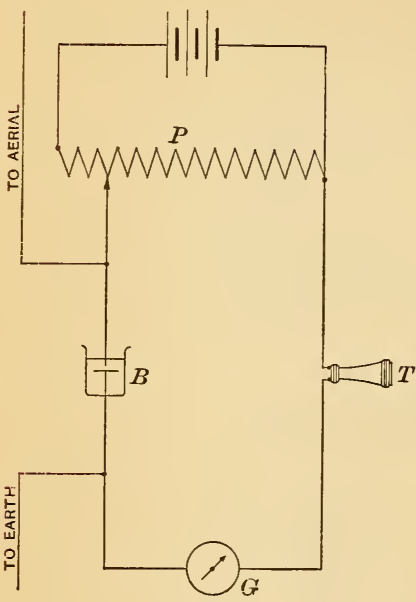

Fig. 4. detector and the polarizing electromotive force; second, the action under positive and negative polarization; third, the sensitiveness using different electrolytes; fourth, the absolute sensitiveness in terms of current and electromotive force.

The arrangement of the apparatus is shown in Fig. 4. The detector $B$ used in most of the experiments was of the type made by the National Electric Signaling Company, and consisted essentially of a minute platinum cup containing the electrolyte into which the tip of platinum wire about $0.002 \mathrm{~mm}$ in diameter dipped. This platinum wire is drawn in silver, the silver being dissolved away in the acid, leaving the bare platinum point ready for use. A galvanometer $G$ and a telephone $T$ were in series with the detector and potentiometer $P$. The aerial and earth connections are shown in the figure.

POSITIVE POLARIZATION OF POINT.

Signals from Coil in Room.-Tables V and VI contain the results of the comparison of several electrolytes in the detector under various polarizing electromotive forces. $\mathrm{HCl}$ is of especial interest as in this case $\mathrm{Cl}$ and not $\mathrm{O}$ is deposited on the point. The much more decided breaking down of resistance as shown on the galvanometer suggests the idea of chemical action, the $\mathrm{Cl}$ attacking the $\mathrm{Pt}$ point more vigorously than $\mathrm{O}$. Table VII shows a comparison of the sensibility for signals from the station of the National Electric Signaling Company. In this case the intensity was measured by observing with how small a shunt around the telephone the signals remained audible. In general at this distance the signals were too weak to produce any breaking down of resistance observabie on the 


\section{TABLE V}

$\mathrm{HCl}$ ( 50 per cent).

Point of $0.002 \mathrm{~mm}$ wire not in glass. Waves from small coil Point Anode

$\begin{array}{lll}\begin{array}{l}\text { Polarizing } \\ \text { E. M. F. }\end{array} & \text { Without waves } & \text { Direct Current } \\ 1.3 \text { volts. } & 0 \times 10^{-6} \mathrm{amp} & \text { With waves } \\ 1.6 & 0 & 0 \times 10^{-6} \mathrm{amp} \\ 1.8 & 0.5 & 3 \\ 2.0 & 0.0 & 4 \\ 2.2 & 0.5 & 8 \\ 2.4 & 1.0 & 25 \\ & & 40\end{array}$

TABLE VI

Point $0.002 \mathrm{~mm}$ wire not in glass. Waves from small coil.

$\begin{array}{llcc} & \text { E. M. F. } & \text { Without waves } & \text { With waves } \\ \mathrm{HCl} 50 \% & 2.4 \text { volts } & 1 \times 10^{-6} \text { amp. } & 40 \times 10^{-6} \text { amp. } \\ \mathrm{HNO}_{3} 20 \% & 1.6 & 5 & 8 \\ \mathrm{H}_{2} \mathrm{SO}_{4} 30 \% & 2.4 & 10 & 5 \\ \mathrm{KOH} \mathrm{30 \%} & 2.6 & 5 & 15\end{array}$

\section{TABLE VII}

Point $0.002 \mathrm{~mm}$ wire not in glass. Waves from station of National Electric Signaling Company.

$\begin{array}{llc} & \begin{array}{c}\text { Polarizing } \\ \text { E. M. F. }\end{array} & \begin{array}{c}\text { Shunt around telephone } \\ \text { For silence }\end{array} \\ \mathrm{HNO}_{3} 20 \% & 2.0 \text { volts } & 100 \text { ohms } \\ \mathrm{H}_{2} \mathrm{SO}_{4} 30 \% & 2.3 & 250 \\ \mathrm{KOH} \mathrm{30 \%} & 2.4 & 300 \\ & 2.7 & 300\end{array}$

Resistance of telephone, I,300 ohms.

galvanometer. On two occasions, however, satisfactory galvanometer observations were also made. It is to be observed that the differences between the sensitiveness of the electrolytes are much smaller than for the stronger signals which affect the galvanometer. $\mathrm{HCl}$ is here also the most sensitive, but while the sensitiveness for distant signals as heard in the telephone is only about twice that of $\mathrm{HNO}_{3}$ the galvanometer deflections were generally five to seven times greater. 


\section{NEGATIVE POLARIZATION OF POINT.}

The question of the sensitiveness of a negatively polarized point is one on which there has been much difference of opinion. Schlömilch and De Forrest claim that there is almost no sensitiveness in this case, while Fessenden and Rothmund and Lessing claim a sensitiveness nearly equal to that with positive polarization. The first experiments with the coil in the laboratory seemed to support Schlömilch ${ }^{8}$ and De Forrest ${ }^{8}$ as no effect could be observed either on the galvanometer or in the telephone from the coil in the room except when the instruments were close together. But when the detector with negatively polarized point was connected to the aerial of the Bureau, signals from the station at the navy-yard and from the National Signaling Company's station were detected with about the same distinctness as with positive polarization. The cause of this difference in sensitiveness to signals from the small coil and to distant signals is extremely difficult to understand. First, it was thought that perhaps the waves from the coil were of too high frequency, but increasing the wave length by means of condensers failed to produce any effect. A second hypothesis was that the direct induction of the coil might produce an effect tending to counterbalance the influence of the waves. It has been already shown in Table IV that with negative polarization alternating currents sometimes produce a decrease of current instead of an increase, and it seems possible that we have here a combination of opposite effects which annul each other. It also seems possible that the difference in behavior was due to the fact that the wave train from the small coil was much more strongly damped than that from the distant station.

\section{THE RESISTANCE OF THE DETECTOR.}

For direct currents the resistance may be taken as the ratio of change in electromotive force to change in current. If the changes in electromotive force are small the numerical value of the change in current is the same whether the electromotive force be increased or decreased. When the polarization is nearly complete, i. e., when very little direct current flows, the resistance is very high; for 
example, in the case of $\mathrm{HCl}$ (50 per cent) using a $0.002 \mathrm{~mm}$ platinum point polarized with 2 volts, an increase or decrease of 0.02 volt changed the current by $\mathrm{I} .5 \times 10^{-6}$ amperes; i. e., the resistance as above defined is about $\mathrm{r} 3,000$ ohms. As it did not seem certain that the resistance would be the same for alternating currents, an experiment was tried with a current of low frequency using the arrangement of apparatus shown in the figure. The resistance of the detector was determined by introducing in $R$ the amount of resistance necessary to cut down by one-half the alternating current in the telephone, the current strength being measured relatively by noting the amount of resistance in the shunt around the telephonc necessary to produce silence. Neglecting the resistance of the (shunted) telephone and the potentiometer, $R$ is equal to the resistance of the detector. In various trials this was found to vary between 9,000 and 15,000 ohms, which agrees with the value found above in the direct current experiments. When the electromotive force from the potentiometer is increased so that more direct current flows the resistance drops rapidly, in one experiment with $\mathrm{HNO}_{3}(2 \mathrm{O}$ per cent) falling to about 300

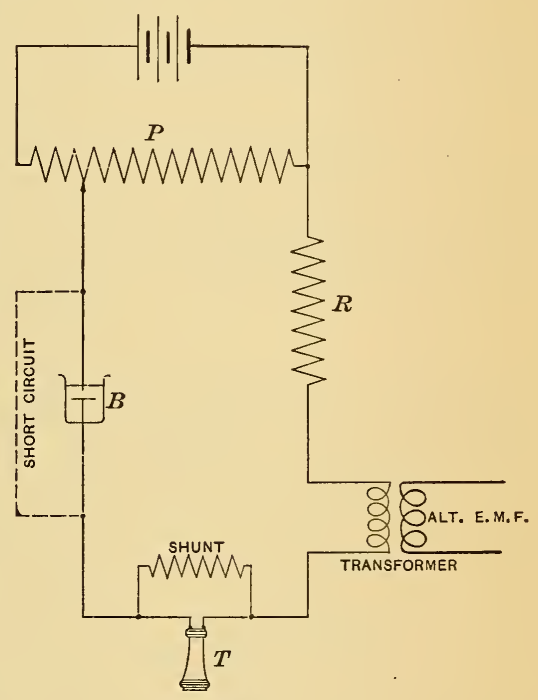

Fig. 5. ohms. When the polarizing electromotive force on the detector was zero the resistance was about roo,ooo ohms. For high frequency oscillations it is probable that the electrolytic capacity of the point may play an important part in the effective resistance.

\section{EFFECT OF HEATING THE POINT ELECTRODE.}

According to Fessenden, ${ }^{9}$ the action of the detector depends to a considerable extent on the heating at the surface of the point due to the passage of the current through the large resistance which

$29572-06-8$

${ }^{9}$ Loc. cit. 
exists there. If this is the case, changes in the resistance between the wire and the liquid must be produced if some way of heating the point can be found. This was accomplished by constructing the small electrode in the form of a wire loop $L$, through which a heating current could be sent, and arranging the circuit as in Fig. 6.

Two sets of experiments were made with this form of apparatus, in the first of which $0.03 \mathrm{~mm}$ wire was used. When an alternating electromotive force of more than o.or volt was applied, the current through the direct circuit was increased, showing that the heating of the wire was sufficient to change the resistance of the cell. As no current could be detected in the galvanometer due to the heating when the polarizing electromotive force was zero, this was considered

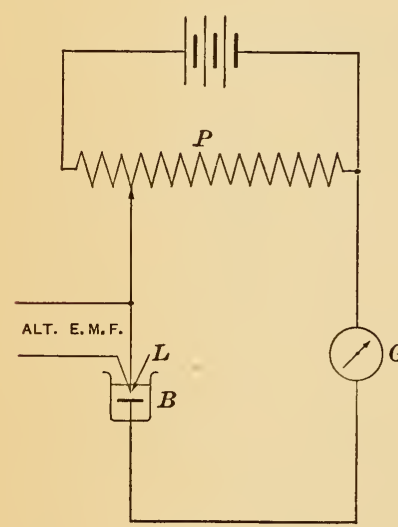

Fig. 6.

to prove that the effect was not due to thermoelectric action. This was also shown by the fact that the change in current was also an increase when the polarizing electromotive force was reversed. The second experiment was similar, except that in this case the loop was formed of $0.002 \mathrm{~mm}$ wire about $\mathrm{I} \mathrm{mm}$ long, giving a resistance of some $50 \mathrm{ohms}$. This was so sensitive that when a telephone receiver was used as the source of alternating current in the loop, a loud shout was enough to increase the current in the galvanometer $G$ by several micro-amperes. As the resistance of the wire loop was small in comparison with that of the detector, it was not considered possible that enough of the alternating current could pass through the main circuit to produce a direct effect on the detector. This heating effect may be explained either by supposing that the change of resistance of the detector is due to a change of resistance in the electrolyte, or what seems more probable it may be due to a direct breaking up of the small polarization bubbles by the expansion of the gas. It indicates at any rate that the heating at the contact of the point electrode with the electrolyte is one of the factors of the phenomenon.

It seems probable that at least with strong signals there are several factors which have a part in producing the change in resistance 
of the detector. The wearing away of the platinum point under the influence of oscillations, but not under direct current, a phenomenon familiar to every wireless operator using these cells, certainly points to chemical action. There is also probably a certain amount of rectification in the alternating current, for it is observed that when an electromotive force has been applied such that the polarization is at the point of breaking down, an increase in the electromotive force of more than about 0.02 volts increases the current more than a similar decrease in electromotive force decreases it. For rapid oscillations when the capacity action of the point electrode becomes prominent the rapid changes in electrostatic attraction across the gas film may tend to break up the minute bubbles mechanically. Estimates of the intensity of the electrical waves from the small coil indicate that the sensitiveness of the electrolytic detector for rapid oscillations does not differ materially from the sensitiveness for slowly alternating currents already determined.

\section{CONCLUSIONS.}

r. The electrolytic detector is sensitive to alternating currents of low frequency, and with a sensitive galvanometer is capable of detecting a few ten-thousandths of a volt. For the stronger alternating currents used, the breaking down in resistance is approximately proportional to the square of the alternating current. For the smaller currents it appears to vary with a lesser power.

2. With increasing polarizing electromotive force the sensitiveness increases to a maximum, after which it remains constant or decreases. This critical electromotive force is not constant, but varies according to the size and condition of the point electrode.

3. Under favorable conditions and with moderate polarization the detector is equally sensitive to alternating currents with the point electrode anode or cathode, but with the point cathode the action is oftener irregular, the resistance sometimes increasing instead of decreasing.

4. The resistance of the detector for slowly alternating currents varies from about 20,000 ohms to 400 ohms, according to the polarizing electromotive force applied. For rapid oscillations the capacity effect of the point electrode may play a part. 
5. For electrical waves from a distance the detector is approximately equally sensitive with the point electrode anode or cathode, but for waves from a coil in the laboratory some cause appears to annul the sensitiveness of the cathode point electrode.

6. When the small electrode is made in the form of a loop of very fine wire and an alternating heating current is sent through it, the resistance of the cell is decreased, indicating that heat is one of the factors in the phenomenon. Probably chemical action, rectification, and electrostatic attraction across the gas film also have a part. 